\title{
O ensino de ciências naturais nos anos iniciais do ensino fundamental: um olhar a partir dos docentes de uma escola da baixada fluminense do Rio de Janeiro
}

\author{
Science education in the initial years of elementary school: a view \\ from teachers of a school in the baixada fluminense of Rio de \\ Janeiro state
}

Maria José Machado Costa ${ }^{1}$

Marcus Vinicius Pereira²

\begin{abstract}
Resumo
O ensino de Ciências Naturais é desvalorizado no ensino fundamental na medida em que passa a ser preconizado pelos próprios sistemas de ensino a partir da construção dos conteúdos mínimos e do tempo destinado para se trabalhar a disciplina em sala de aula. A fim de investigarmos esse pressuposto, apresentamos neste artigo um estudo sobre as práticas pedagógicas desenvolvidas por professoras dos anos iniciais do ensino fundamental no âmbito do ensino de Ciências Naturais. Para tal, foi realizada uma pesquisa de campo com 18 professoras em uma escola municipal na região da Baixada Fluminense do estado do Rio de Janeiro. Constatou-se que os conteúdos são trabalhados a partir do livro didático pelas professoras, que, por sua vez, apresentam dificuldade em desenvolver atividades prático-experimentais, consideradas essenciais no ensino de Ciências Naturais. Dessa forma, é responsabilidade da secretaria de educação reavaliar o ensino de Ciências Naturais, se debruçando sobre a formação dos professores para trabalharem essa disciplina com a implantação de programas de formação continuada em serviço e melhoria das condições de trabalho.
\end{abstract}

Palavras-chave: Prática docente. Ensino fundamental. Ensino de Ciências Naturais.

\begin{abstract}
The teaching of Natural Sciences is devalued in the elementary school to the extent that it starts to be recommended by the education systems themselves, based on the construction of the minimum contents and the time destined to work the science discipline in the classroom. In order to investigate this assumption, we present in this article a study on the pedagogical practices developed by teachers of the initial years of elementary

\footnotetext{
${ }^{1}$ A autora é Mestra em Ensino de Ciências do Curso Mestrado Acadêmico do Programa de Pós-Graduação Stricto Sensu em Ensino de Ciências do Instituto Federal de Educação Ciência e Tecnologia do Estado do Rio de Janeiro - IFRJ. E-mail: mzezinhacosta@gmail.com

${ }^{2} \mathrm{O}$ autor é Doutor em Educação em Ciências e Saúde (2013) pela Universidade Federal do Rio de Janeiro (UFRJ). É pós-doutorando pela Faculdade de Educação da Universidade de São Paulo (FE-USP).E-mail: marcus.pereira@ifrj.edu.br
} 
education in the scope of the teaching of Natural Sciences. For this study, a field survey was carried out with 18 teachers at a municipal school in the Baixada Fluminense region of the state of Rio de Janeiro. It was verified that the contents are worked from the didactic book by the teachers, who, in turn, have difficulty in developing practical-experimental activities, essential in the teaching of Natural Sciences. Thus, it is the responsibility of the education department to re-evaluate the teaching of Natural Sciences, focusing on the training of teachers to work this discipline with the implementation of continuing education programs in service and improvement of working conditions.

Keywords: Teaching practice. Elementary school. Science education.

\section{PROBLEMATIZAÇÃo}

A educação é uma prática social que existe em toda e qualquer sociedade humana, em todos os tempos e lugares. A forma de transmissão do saber às novas gerações, primeiramente, ocorre no ambiente familiar, onde tem início o processo educacional. "Não há povo em que não exista certo número de ideias, de sentimentos e de práticas que a educação deve difundir para todas as crianças, indistintamente, seja qual for à categoria social a que pertençam" (DURKHEIM, 2011, p. 53). Apesar da definição de Durkheim corresponder às exigências do conjunto da sociedade, na legislação educacional corresponde ao que se conhece por currículo mínimo, isto é, aquilo que cabe às escolas de todo o país praticarem sua dinâmica cotidiana aos públicos escolares. A prática escolar, com suas ações educacionais, tem intencionalidade em seu exercício e isso a diferencia de todas as outras práticas sociais, que, independentemente do lugar e do tempo, tem a finalidade de inserir as novas gerações no mundo. Por isso, é necessário que a escola tenha profissionais especializados na arte da construção do saber, entre os principais atores dessa dinâmica escolar o professor e o aluno. Compreendendo esse espaço como um meio de interação e construção de conhecimentos, o ensino exerce uma ação fundamental no processo de tornar possivel a dinâmica da aprendizagem, que somente se consolida quando tem significado para o estudante, ou seja, quando ele percebe a necessidade de se apropriar desse saber para facilitar o seu cotidiano. 
Nessa premissa, Freire (1992, p. 102) define a aprendizagem significativa como “[...] aquela que ocorre a partir da compreensão pessoal por parte de quem aprende, possibilitando a reconstrução de conceitos que ampliam a habilidade de aprender cada vez mais o que desencadeia uma atitude ativa diante da vida". Portanto, o ato de ensinar necessita fundamentar-se na relação recíproca entre professor e aluno, promovendo a construção do raciocínio lógico e dialógico, onde os dois são coadjuvantes na construção desse saber, denotando a importância que a escola adquiriu no mundo moderno. Cabe à escola a grandiosa tarefa de formar as novas gerações para um mundo em constante mudança, demonstrando a sua responsabilidade em mediar à consolidação do conhecimento pelo aluno. Dessa forma, a escola tem como foco principal em seu trabalho educacional o desenvolvimento de todas as habilidades que são fundamentais e necessárias para o aluno ter condição de enfrentamento das demandas habituais na contemporaneidade. Tendo como pano de fundo as contínuas e rápidas modificações e transformações que ocorrem no mundo moderno, passou-se a exigir um corpo de profissionais atuantes no cenário escolar cada vez mais competente e comprometido com o que faz.

Nesse viés, é importante que a prática pedagógica do professor se fundamente como uma ação crítica e emancipadora, empenhada na relação entre o pensar e o fazer, momento imprescindivel de contínua reflexão, uma vez que o próprio educador, muitas vezes, pensando que age em nome da liberdade, pode estar legitimando as condições exigidas por uma determinada estrutura social. As ações pedagógicas do professor precisam estar comprometidas com o despertar do interesse dos alunos desde os anos iniciais do Ensino Fundamental (EF) e, em especial, nas aulas de Ciências Naturais, objeto de estudo desse trabalho.

A busca incessante pelo interesse do aluno é um dos desafios a ser superado pelos docentes ao ensinar, especialmente nessa componente curricular, no entanto nem sempre essa meta é alcançada, conforme justificam Carvalho e Gil-Perez, (2001, p. 107), “[...] talvez porque os conteúdos trabalhados dentro do ambiente escolar são apresentados como provenientes de uma ciência 'pronta', onde não há espaço para discussões 
acerca de seus fenômenos”. É, portanto, fundamental uma ruptura na condição ingênua da ação pedagógica do professor de Ciências Naturais, que proporcione aos estudantes desafios que, de fato, se traduzam na aplicação constante dos conhecimentos construídos em aula na sua vida cotidiana. Essa ação pedagógica promove e estabelece estratégias de organização, estimula os alunos a fazerem escolhas e a se comprometerem com elas. "Ao assumir responsabilidades, possibilita a realização de um trabalho coletivo e interdisciplinar" (HERNANDEZ; VENTURA, 1998, p.103).

Aliado a essas questões, tem-se o grande desafio de tornar o ensino de Ciências Naturais prazeroso e instigante, sendo capaz de desenvolver no aluno uma educação científica. Conforme defende Brandi e Gurgel (2002, p.113):

Pensar é, sobretudo, dar sentido ao que somos e ao que nos acontece. Para que o pensamento científico seja incorporado pelo educando como uma prática de seu cotidiano é preciso que a Ciência esteja ao seu alcance e o conhecimento tenha sentido e possa ser utilizado na compreensão da realidade que o cerca.

Diante desse panorama, considerando a necessidade do processo pedagógico renovar-se continuamente para atender, sobretudo, às expectativas dos alunos, neste artigo temos como objetivo investigar as práticas pedagógicas de professores ao ensinarem Ciências Naturais nos anos iniciais do Ensino Fundamental em uma escola municipal localizada na cidade de Itaguaí, região da Baixada Fluminense do estado do Rio de Janeiro.

\section{METODOLOGIA}

Esta pesquisa inclui evidências qualitativas com características descritivas e se configura como uma pesquisa de campo, e foi desenvolvida em uma escola municipal localizada no município de Itaguaí, uma das cidades que compõe a região da Baixada Fluminense do estado do Rio de Janeiro. O universo é composto por 18 professoras que trabalham com turmas do $1^{\circ}$ ao $5^{\circ}$ ano do $\mathrm{EF}$, nos turnos matutino e vespertino. 
A coleta de dados foi realizada em duas etapas, sendo a primeira o levantamento do perfil profissional das professoras. Para tanto foi utilizado um questionário contendo, além dos dados de identificação (idade, tempo de profissão, ano de entrada na escola e telefone), cinco questões que tinham como objetivo sondar a formação e a experiência profissional para docência nos anos iniciais. $\mathrm{Na}$ segunda etapa, foram realizadas entrevistas semiestruturadas em que buscamos investigar a atuação profissional no ensino de Ciências Naturais e a prática pedagógica desenvolvida em sala de aula. As entrevistas foram realizadas com todas as 18 professoras, de forma que estivessem presentes apenas os sujeitos da pesquisa, ou seja, o professor e a pesquisadora, para que não houvesse nenhum tipo de influência e/ou propagação de ideias antes do momento da entrevista em si. Foi estabelecido com cada professora um vínculo de descrição ética no sentido de evitar comentários no grupo docente sobre as questões abordadas na entrevista para preservar a integridade dos dados levantados nesse momento, além de garantir princípios éticos intrínsecos à pesquisa com seres humanos. A entrevista foi previamente validada com professores itinerantes da escola, que não participaram diretamente da pesquisa e, portanto, não compõem a amostra dos 18 sujeitos.

Também foram realizadas observações aleatórias de algumas aulas, e o diário de campo foi uma fonte de informações relevantes à pesquisa, até porque esses registros se transformaram em objetos de análise e releitura, facilitando a compreensão da realidade pesquisada. Os seguintes documentos somaram-se ao corpus de análise: planejamentos feitos pelas professoras, atividades escritas (folhinhas de tarefa), regimento escolar e o projeto político-pedagógico da escola, sempre orientados pelos objetivos e questões formuladas com base no problema que fora estabelecido, como o caminho a ser percorrido procurando entender como os professores dos anos iniciais trabalham (ou não) Ciências Naturais em seu cotidiano escolar. No entanto, o que se tornou fonte de dados efetivos para consolidação da pesquisa foi o levantamento do perfil profissional e as entrevistas semiestruturadas, embora os outros objetos de análise contribuíram para legitimar os resultados. 


\section{DADOS E RESULTADOS}

\section{Primeira etapa}

Das 18 professoras, 16 trabalham 20 horas semanais e apenas duas trabalham 40 horas, inseridas em um programa de "dobra" de carga horária (e salário) instituído pela Prefeitura Municipal de Itaguaí (PMI) como estratégia para suprir a falta de docentes, ou seja, devido a carência de professores, há a opção de um docente concursado ocupar a vacância a fim de não deixar turmas sem aulas, recebendo, para isso, salário dobrado pelo aumento de sua carga horária. Utilizamos a flexão no gênero feminino "professora" pelo fato de todo o quadro docente dos anos iniciais dessa escola ser composto por mulheres, todas concursadas e empossadas como funcionárias públicas com cargo de docente da PMI.

A atenção à carga horária é fundamental, já que quanto mais as professoras vivenciam as relações dentro dessa escola, melhor podem compreender seu real contexto e se relacionar mais efetivamente com seus alunos e a comunidade, mas deixamos claro que não defendemos a dupla jornada em sala de aula para um mesmo profissional docente, já que o tempo remunerado para planejamento é essencial.

No levantamento do perfil, quanto ao tempo de magistério, quatro professoras exercem a profissão entre 1 e 5 anos, quatro, entre 6 e 10 anos, duas, entre 11 e 15, três, entre 16 e 20, três, entre 20 e 26 e duas, entre 26 e 30. Em relação à formação, 14 professoras são licenciadas e apenas 4 têm formação no Ensino Médio - Curso Formação de Professores (Curso Normal). Cinco professoras entraram na graduação em instituições privadas graças a convênios firmados entre a Secretaria Municipal de Educação e Cultura (SMEC) e as universidades na Baixada Fluminense do RJ próximas ao Município de Itaguaí, concedendo descontos nas mensalidades para os servidores da PMI. As outras cinco professoras que cursaram graduação em universidades privadas custearam sozinhas sua formação, pois desejaram estudar mais próximo de suas residências. Há ainda quatro professoras que são graduadas em universidades públicas de ensino, conforme evidencia o Quadro 1 com o perfil das 18 professoras sujeitos da pesquisa, em que destacamos o fato de que nenhuma delas possui formação específica na área 
de Ciências Naturais, seja na graduação ou em formação continuada. Na apresentação dos resultados, os nomes das professoras foram omitidos a fim de preservar sua identidade, de forma que usamos a nomenclatura $\mathrm{P}$ (professora) seguida da numeração em algarismos arábicos de 1 a 18 no que se refere a cada uma. Em relação à pós-graduação, oito professoras fizeram curso de especialização, seis já concluíram e duas estão em fase de conclusão, nas seguintes áreas: Administração e Supervisão Escolar (P10), Psicopedagogia Clínica e Institucional (P1 e P2), Administração Escolar (P6), Coordenação e Gestão Educacional (P5), Orientação Educacional e Supervisão Escolar (P9), Supervisão Educacional (P14) e Gestão Integrada (P13).

Assim como em relação à graduação, nenhuma das professoras cursa / cursou pós-graduação na área de Ensino de Ciências, evidenciando que houve um interesse em aperfeiçoar-se em áreas relacionadas à área de educação em um sentido mais estrito. Seis das 14 professoras que possuem nivel superior (P3, P4, P7, P8, P11 e P12) não possuem e nem estão cursando pós-graduação. As professoras P15 a P18 têm apenas o Ensino Médio na modalidade Normal (Curso Normal), e não estão cursando graduação. Outra questão, não apresentada no Quadro 1, diz respeito a cursos que não são da área educacional: P11 concluiu curso de contabilidade geral e P13 que concluiu o curso de especialização em deficiência mental. Todas as demais descreveram que apenas participam das formações continuadas promovidas pela coordenação geral dos anos iniciais da SMEC. Nenhuma das professoras mencionou a participação em seminários, congressos, fórum de debates etc.. 


\section{Quadro 1 - Perfil de formação das professoras}

\begin{tabular}{|c|c|c|c|}
\hline $\mathbf{P}$ & FORMAÇÃO INICIAL & INSTITUIÇÃO & PÓS-GRADUAÇÃO \\
\hline $\mathrm{P} 1$ & Português / Literatura & Particular & $\begin{array}{l}\text { Psicopedagogia Clinica e } \\
\text { Institucional }\end{array}$ \\
\hline P2 & Português / Literatura & Particular & $\begin{array}{l}\text { Psicopedagogia Clínica e } \\
\text { Institucional }\end{array}$ \\
\hline P3 & Português / Literatura & Pública & - \\
\hline P4 & Português / Literatura & Pública & - \\
\hline P5 & Matemática & Particular & $\begin{array}{l}\text { Coordenação e Gestão } \\
\text { Educacional }\end{array}$ \\
\hline P6 & Matemática & Particular & Administração Escolar \\
\hline P7 & Matemática & Pública & - \\
\hline P8 & História & Particular & - \\
\hline P9 & História & Particular & $\begin{array}{l}\text { Orientação Educacional e } \\
\text { Supervisão Escolar }\end{array}$ \\
\hline P10 & Geografia & Particular & $\begin{array}{c}\text { Administração e Supervisão } \\
\text { Escolar }\end{array}$ \\
\hline P11 & Geografia & Particular & - \\
\hline P12 & Pedagogia & Particular & - \\
\hline P13 & Pedagogia & Particular & Gestão Integrada \\
\hline P14 & Pedagogia & Pública & Supervisão Educacional \\
\hline P15 & Curso Normal & Particular & - \\
\hline P16 & Curso Normal & Particular & - \\
\hline P17 & Curso Normal & Pública & - \\
\hline P18 & Curso Normal & Pública & - \\
\hline
\end{tabular}

Por último, sobre o exercício da função docente nos anos iniciais em outra rede de ensino, quatro professoras atuam na rede pública de ensino em outros municípios do Rio de Janeiro (P2, P3, P5 e P7, respectivamente com 21, 2, 8 e 4 anos de exercício na função) e duas, na rede privada (P4 e P12, com respectivamente 3 e 2 anos). 


\section{Segunda etapa}

Uma vez melhor conhecido o perfil das docentes, na segunda etapa da pesquisa a coleta de dados se deu a partir de entrevistas semiestruturadas, quando todas concordaram em participar apesar de a maioria declarar não se sentir a vontade em ter suas falas gravadas em áudio. Dessa forma, optou-se apenas pelo registro escrito em diário de pesquisa, proporcionando, assim, um clima mais confiável e confortável para as professoras. Havia certo temor dessas professoras em expor suas dificuldades e angústias, talvez devido a experiências anteriores, acadêmicas e/ou institucionais, mal sucedidas, embora demonstrassem clareza sobre as questões éticas que permeiam o processo de pesquisa explanadas pela pesquisadora. A partir desse momento, a entrevista assumiu uma postura solidária de conversa.

Primeiramente, indagou-se sobre a prática docente em seu cotidiano com objetivo de perceber sua concepção sobre educação, e, consequentemente, compreender como ensinam Ciências Naturais nos anos iniciais, quais os recursos que são utilizados e se promovem desafios aos alunos. Das 18 professoras entrevistadas, quatro (P1, P2, P13 e P14) afirmaram conhecer e utilizar uma proposta construtivista em suas aulas; três (P9, P12 e P10) relataram mesclar o construtivismo e o tradicional, sete (P3, P4, P7, P15, P16, P17 e P18) indicaram já ter ouvido falar do construtivismo, mas que não usavam para ensinar, pois costumavam trabalhar, normalmente, passando o trabalho no quadro e usando o livro, e quatro (P5, P8, P6 e P11) assumiram fazer uso de uma concepção tradicional ao ensinar, mesmo afirmando conhecer o construtivismo. Alguns trechos das falas das professoras evidenciam essas respostas, que foram agrupadas de acordo com a categoria de resposta (padrão que será adotado também para as questões subsequentes, uma vez que algumas respostas são transcrições e outras anotações no diário de campo):

Eu não sei bem explicar sobre a concepção de educação que fundamenta meu trabalho, mas sei que é o construtivismo. Para ensinar ciências eu gosto de levar meu aluno para o pátio em busca de plantas para mostrar as partes das plantas, etc. [...] eu sou contra o tradicional. (P1 e P14)

Nas aulas de ciências eu ia trabalhar as sementes das plantas, mas naquele dia um aluno trouxe uma borboleta para a hora da 
novidade e eu aproveitei, mudei toda minha aula [...]. É aposto no construtivismo porque o aluno constrói suas próprias atividades [...]. Os alunos na sala de aula se tornam mais criativo. (P2 e P13)

Eu não tenho muito conhecimento dessas teorias que fundamentam o meu trabalho e essas novas concepções de aprendizagem, mas pelo que entendo eu uso um pouco do tradicional e um pouco do construtivismo. Por isso, é que eu te digo: eu vim entender mais depois que fiz o curso de graduação, porque eu estava estudando essas teorias e ai na escola eu procurei me aprofundar [...] exatamente porque estava trabalhando com ela. (P9, P10 e P12)

Destacam-se, a seguir, alguns trechos que evidenciam respostas em relação às sete professoras que afirmaram conhecer, mas não usar, o construtivismo, trabalhando com o tradicional que não souberam ou não quiserem nomear.

Às vezes eu acho chato esse negócio do aluno ficar só copiando do quadro, mas também é nesse momento que eu aproveito para resolver algumas coisas, por exemplo, lançar algo no diário [...] o negócio é manter o aluno ocupado, ai eles ficam quietos. (P3 e P4)

Eu percebo que com o construtivismo o aluno se sente mais à vontade para falar, ele se sente tão liberal para falar que ele acaba até atrapalhando a aula, é bom em ciências que ele participa legal. Eu, às vezes, sou de acordo com o tradicional, mas muitas vezes não. (P7)

Eu não sei bem explicar sobre a concepção de educação que uso no meu trabalho. Mas do jeito que trabalho dá resultado eles aprendem. Só que aqueles que não querem nada, aí fica difícil [...]. A gente ensina do jeito normal como todo professor faz [...]. Têm alunos mesmo que tem dificuldades, que eu acho que trabalhando com ele com cópia, com pontilhados, etc., seria mais fácil. [...] mas, isso é tradicional. (P15, P16, P17 e P18)

As demais professoras relataram conhecer a proposta construtivista, porém não acreditam em nenhuma concepção teórica que nada tenha relação com a prática de sala de aula, verbalizando que usam o tradicional e é isso que funciona.

As coordenadoras da SMEC querem mandar na nossa sala de aula. Trazem muitas novidades tentam passar uma forma de trabalhar que não dá certo com esses alunos. [...] $O$ construtivismo [...] que nada, essas teorias fazem uma confusão na nossa cabeça. (P5)

Já vieram outros coordenadores aqui na escola passar outras formas de ensinar que está no dia a dia, como se isso fosse 
muito moderno e prático. Hoje, o que é moderno é aquilo que é prático e simples, é como nossos pais, aprenderam no tradicional, esse sim funciona. (P6 e P11)

Os alunos fazem outros trabalhos diferentes do que se faz na escola, trabalhos de jogos, de não sei mais o quê. Eles não tão acostumados assim [...] o negócio deles mesmo é só sala de aula e eu acho que é o que rende, na verdade eles precisam aprender a ler e escrever. (P8)

A partir das falas dessas professoras, podemos constatar a necessidade em utilizar ações pautadas nas práticas tradicionais, que promovem a passividade do aluno, baseadas numa investida de cima para baixo, preconizando o autoritarismo como elemento de respeito e soberania e que, infelizmente, em nada contribui para a aprendizagem criativa do aluno. Muito ao contrário, acaba estimulando o aluno a memorizar o conteúdo para repeti-lo quando cobrado e que possivelmente será esquecido. De forma geral, trata-se de uma concepção em que não é atribuída a devida importância ao desenvolvimento da aprendizagem que tenha significado para o aluno. Existem dificuldades apresentadas pelas professoras, dentre elas está a organização dos conteúdos e das atividades a serem trabalhadas nas diversas disciplinas e em especial em Ciências Naturais, evidenciada pelas falas destacadas a seguir.

Reuniões de planejamentos não acontecem porque são marcadas pela SMEC e lá se fala de tudo menos do que de ensinar e como se ensinar. Falam, falam, e acabam não contribuindo em nada com o nosso trabalho na escola. (P5)

Tem o planejamento que a Lei exige para a gente cumprir, mas o que é bom é que nós podemos ficar em casa e agirem várias coisas [...]. Olha, eu faço o meu plano aqui mesmo na sala enquanto os alunos estão copiando o trabalho do quadro. (P18)

Quando a gente não sabe o que vai trabalhar a gente procura nos livros didáticos de autores diferentes daquele da nossa turma e copia a matéria. (P5 e P11)

Eu faço aquilo que acho correto, procuro o conteúdo em planos de colegas que trabalharam naquela série no ano anterior. Agora sinto falta do plano construido com outras colegas da mesma série. (P2 e P3)

Os relatos dessas professoras consolidam uma ação individual ao preparar o planejamento de sua aula e ao selecionar o conteúdo, não ocorrendo na escola nenhum encontro de planejamento conjunto ou pelo 
menos com as professoras que estão trabalhando no mesmo ano de escolaridade. Os encontros de planejamento quinzenal ou mensal são convocados pela SMEC e acabam tendo uma dinâmica pouco favorável à discussão conjunta dos professores, pois ficam todos os professores juntos em um mesmo espaço, mas com diferentes anos de escolaridade. As falas das professoras foram bastante significativas nesse processo, pois se efetivam no âmbito profissional e pessoal, provocando muita insegurança na ação docente. O livro didático é utilizado como uma única estratégia de ensino e, a partir das observações, constata-se que as dificuldades enfrentadas por essas professoras são imensas, e vão desde a falta de material didático imprescindível à prática pedagógica, a indisponibilidade dos recursos necessários, as dificuldades de organização da escola, até a falta de conhecimento, acompanhamento e informação acerca da sua prática pedagógica. Nesse contexto, são destacadas algumas respostas concedidas durante a entrevista em relação à forma como as professoras utilizam o livro didático:

O livro é muito importante, porque enquanto os alunos fazem a atividade do livro eu consigo ajudar o aluno que está com dificuldade. (P7)

Toda a matéria que eu preciso trabalhar tem no livro, ai eu uso o livro deixo eles fazendo o trabalho, enquanto eu passo o dever no quadro. (P5 e P10)

O livro de Ciências tem poucas páginas, mas o de Matemática e Português têm muitas páginas, então tem que dar tempo de usar tudo se não os pais vêm reclamar na escola. (P16 e P17)

É [...] complicado porque fica tudo por conta do professor, então eu uso o livro porque mantém o aluno ocupado e eles não fazem bagunça. (P12 e P18)

É importante destacar que em relação ao ensino de Ciências Naturais, a conduta cotidiana das professoras é a mesma. Ampliando o olhar frente à prática pedagógica dessas professoras que atuam nos anos iniciais do EF, buscou-se investigar como essas professoras avaliam a aprendizagem dos seus alunos. Foram indagadas questões inerentes à prática docente ao avaliar o desenvolvimento dos alunos no cotidiano escolar. Muitas são as dúvidas e arrochos enfrentados pelas professoras quando se inicia uma reflexão sobre avaliação educacional. Analisando um pouco mais sobre o 
assunto, observa-se que o problema maior repousa na pouca aprendizagem dos alunos e na falta de qualidade do ensino. Frente a isso, o papel dos coordenadores pedagógicos junto ao trabalho das professoras na escola pesquisada não pode distanciar-se do compromisso com a realização de estudos, nos moldes da formação continuada em serviço. Seguem trechos que foram destacados envolvendo a fala das professoras quanto à avaliação da aprendizagem dos alunos, demonstrando que todas apenas nomeiam os instrumentos que utilizam para avaliar:

Eu uso o teste e a provinha, mando bilhete para os pais para botar o aluno pra estudar e no dia marcado eu aplico a prova. Enquanto eles vão fazendo eu vou olhando cada um em suas carteiras. (P13)

Bem a coordenadora passa um calendário de provas aí a gente marca com o aluno, manda bilhete para casa. [...] uso folhinhas de trabalhinhos $e$ o teste depois junto os pontos e lança no diário. (P15)

Sabe eu dou ponto pelo caderno, pelo livro, pelo capricho com tudo, e também por eles se comportarem. Há teste, prova e trabalhinhos que levam pra casa também. (P11)

Avaliar [...] é difícil porque os alunos que eu peguei não sabem nada, não consegue ler nada, como vou fazer [...]A gente tem que dar a nota ai eu dou uma prova vou lendo para eles e eles tentam fazer. (P17).

Trabalhar a avaliação, eu faço atividades diversificadas de acordo com as necessidades de cada aluno. Mas, aplico prova também, é a exigência. (P1).

Quanto à seleção dos conteúdos de Ciências Naturais, esse é feito pelas professoras a partir dos livros didáticos e fundamentado em planejamentos dos anos anteriores, levando em consideração o ano de escolaridade, sendo que a ênfase é dada apenas ao conteúdo, isto é, conceitos que são apresentados ao aluno de forma descontextualizada. Foi possivel detectar que existe uma grande preocupação com a sistematização dos conteúdos a serem memorizados, não levando em consideração o conhecimento já adquirido e historicamente construído pelo aluno. Aprofundando as observações em sala de aula e tendo como pano de fundo o relato das professoras sobre sua ação pedagógica ao ensinar Ciências, percebe-se que elas não têm uma rotina semanal para trabalhar os conteúdos dessa componente curricular. 
É eu faço o planejamento da aula de Ciências, mas não trabalho toda semana. [...] porque a cobrança do PNAIC é grande. Sabe como é? (P17 e P18)

Olha, eu não vou mentir não. Mas como é muito mais importante trabalhar Português e Matemática, eu só trabalho Ciências quando dá. (P7, P8, e P10)

Eu trabalho Ciências da seguinte forma, quando não consigo planejar o que vou dar, ai eu pego o livro e dou para eles fazerem o trabalho [...] e na prova eu dou uma coisa bem simples para dar nota. (P15 e P11)

O tempo de trabalhar Ciências é muito pequeno porque tenho que trabalhar mais Português e Matemática por causa da provinha Brasil. (P2 e P5)

Esses relatos, quando olhados a luz do perfil de formação das professoras levantado na primeira etapa, demonstram que o tempo de magistério não foi um fator determinante para a valorização do ensino de Ciências Naturais nas séries iniciais e que as atividades desenvolvidas para se ensinar são neutras. Embora se tenha no grupo pesquisado professoras com dez ou mais anos de experiência e que nunca participaram de atividades de formação continuada, este pode ser um fator relevante na conduta da mesmice, a qual resulta em sua ação pedagógica. Assim como foram também identificadas professoras com menos de cinco anos no magistério que se predispõem a modificar sua prática por acreditar que a apropriação de novos conhecimentos pedagógicos pode agregar valor a sua prática cotidiana e, consequentemente, ser fator motivacional para os alunos. Destaca-se, ainda, que todas as professoras preparam um quadro de organização semanal das disciplinas a serem trabalhadas em cada um dos dias de aula durante a semana, revelando o tempo destinado às atividades de ensino e a organização das rotinas em sala de aula, e as Ciências Naturais dividem a terça-feira com a Matemática. No entanto, na observação aleatória das aulas, fica notória a maior ênfase destinada aos conteúdos de Matemática e Português, o que pode estar associado à exigência da SMEC em função das avaliações externas (como a Provinha Brasil). Também foi possivel identificar que mesmo com um dia e horário previsto para se ensinar Ciências Naturais isso não acontece na maioria das turmas observadas, podendo de fato não ocorrer, ou ser trabalhada de forma quinzenal e até mesmo mensal, revelando o processo superficial ao ensinar 
Ciências Naturais, apesar de afirmarem reconhecer a importância do trabalho desta disciplina.

\section{DISCUSSÃO}

O tempo de docência é importante para a incorporação de novos saberes, que servem de fundamentos à ação docente, neste caso específico, à ação docente nos anos iniciais do EF. Dessa forma, para contribuir com esse argumento, Tardif (2002, p. 39) defende que:

Os saberes são elementos constitutivos da prática docente. $\mathrm{O}$ professor deve conhecer sua matéria, sua disciplina e seu programa, essas múltiplas articulações entre prática docente e os saberes fazem dos professores um grupo social e profissionais cuja existência depende, em grande parte, de sua capacidade de dominar integrar e mobilizar tais saberes.

A experiência de atuação profissional nos anos iniciais das professoras que atuam na escola pesquisada é condição imprescindivel para o desenvolvimento de uma prática crítica dialógica. O tempo de atuação conduz o professor incorporar um conjunto de saberes, de técnicas e de métodos que são importantes na condução do trabalho docente, diferente de um professor iniciante na carreira. Nesse movimento, pode-se refletir sobre o tempo de atuação no magistério das professoras, o que sugere uma prática em sala de aula que pudesse desenvolver a criticidade dos alunos. Porém, ficou aparente que o fator tempo não é preponderante para abolir práticas pautadas no tradicionalismo, em que o professor deposita o conhecimento nos seus alunos acreditando que eles são desprovidos de seus próprios pensamentos. O aluno não pode ser considerado como uma folha de papel em branco que se deva encher de conteúdos, prática da educação bancária, educar é constituir o sujeito em transformação, e essa postura é considerada educação emancipatória. Nesse sentido, Freire (1996, p. 82), defende que:

A priorização da 'relação dialógica' no ensino que permite o respeito à cultura do aluno, à valorização do conhecimento que o educando traz, enfim, um trabalho a partir da visão do mundo do educando é sem dúvida um dos eixos fundamentais sobre os quais deve se apoiar a prática pedagógica de professores e professoras. 
A experiência docente exerce papel importante na prática pedagógica desenvolvida, principalmente nos anos iniciais pelo fato de ser a base estabelecida na construção do saber acadêmico pelo aluno. Embora isso não seja um referencial engessado que traduza uma prática pedagógica pautada em estabelecer uma prática crítica e dialógica, pois outros fatores perpassam sobre a dinâmica cotidiana das professoras pesquisadas e que, infelizmente, contribuem para uma prática enraizada no posicionamento tradicional de transmissão de conteúdo.

Ficou também evidente a necessidade da formação continuada em serviço. De acordo com Nóvoa (1995, p. 280), “[...] não há ensino de qualidade e inovação pedagógica sem uma adequada formação de professores". Essa formação precisa ser consistente, tanto a inicial quanto a continuada, torna-se essencial na compreensão crítico reflexiva da fundamentação teórico prática de todas as relações que fundamentam o fazer pedagógico dentro da escola. A formação superior de 14 das 18 professoras demonstra um dado importante, já que há uma melhoria significativa no nivel de formação dos docentes para os anos iniciais do EF, e esta é uma condição a ser considerada para que haja uma ressignificação das práticas pedagógicas cotidianas que tendem a cair no arcabouço tradicional. Por outro lado, esse aspecto não acompanha o interesse pela área de formação em Ciências Naturais, o que vai ao encontro da afirmação de Carvalho e Gil-Pérez (2003), quando destacam que a formação dos professores para essa disciplina é deficiente e necessita ser transformada, pois os docentes precisam compreender a matéria a ser ensinada, a fim de orientar e avaliar conscientemente os trabalhos desenvolvidos pelos alunos, superando, assim, o conhecimento espontâneo. A formação e a prática pedagógica necessitam, portanto, serem impregnadas por tais preocupações didático-metodológicas. Essa realidade causa dificuldades na prática docente cotidiana ao ensinar e, portanto, culminam em ações tradicionais que, geralmente, se resumem a cópia da matéria escrita pelo professor no quadro e a utilização exclusiva do livro didático ao ensinar Ciências Naturais. Esse fator realmente se apresenta como uma das justificativas em não utilizar 
atividades que despertem um interesse maior por parte dos alunos. Em relação a isso:

É preciso incentivar uma maior assimilação pessoal dos professores com o local de trabalho [...]. A experiência dos professores nessas escolas é condição imprescindivel para o desenvolvimento de uma prática crítico dialógica, sendo que, ao longo do tempo, o professor vai incorporando um conjunto de saberes, de técnicas e de métodos que são importantes na condução do trabalho docente, diferentemente de um professor iniciante (NÓVOA, 1999, p. 24).

Freire (1996) incentiva os educadores a refletirem sobre o seu fazer pedagógico, modificando aquilo que acha necessário, aperfeiçoando seu trabalho, além de buscar fazer a cada dia o melhor, não de forma ingênua, mas com a certeza de que, se há tentativas, há esperanças e possibilidades de mudanças daquilo que em sua visão precisa ser mudado. Além disso, devem ser considerados ausência de recursos materiais para desenvolver a ação pedagógica, a má formação que os professores têm nas escolas de Ensino Médio (curso Normal), a falta de políticas de acompanhamento do discente, a negligência familiar e a indisciplina em sala de aula.

No discurso das professoras há relatos que demonstram a necessidade de uma formação continuada, condição importante para trazer novos significados a sua prática docente. Esse é um anseio constante delas que procuram entender as concepções que fundamentam sua prática profissional e o ensino de Ciências Naturais. Existe necessidade de se discutir sobre os fundamentos teóricos que consolidam e contribuem para uma educação de qualidade, essa questão tem como viés a discussão da formação continuada dos professores e o acompanhamento pedagógico constante em seu local de trabalho. Conforme afirma Nóvoa (1995, p.280), a “mudança educacional depende dos professores e da sua formação [...], já que não há a menor dúvida de que a criatividade, a problematização, a descoberta, docente e discente, estão completamente entrelaçadas na ação educativa". Contudo, percebe-se ainda que é fundamental o acompanhamento pedagógico dentro da escola e que contribua com proposta de atividades para a aprendizagem dos alunos e não obtenha um caráter fiscalizador, que só desfavorece a imagem do profissional. 
Em relação às formações continuadas promovidas pela SMEC, dez professoras, em caráter de observação e certo pesar, disseram que quase sempre essas formações não trazem contribuições para o enriquecimento da sua prática pedagógica, sem promover troca de experiências e aprofundamento de saberes entre as professoras por meio de estudo de casos, boas práticas, estudo sobre teoria e prática cotidiana das aulas desenvolvidas e, principalmente, sobre o ensino de Ciências Naturais, dentre outras atividades que pudessem constantemente enriquecer o trabalho pedagógico. A esse respeito, Nóvoa (1995, p. 26) enfatiza que a

[...] troca de experiências e a partilha de saberes consolidam espaços de formação continua, nos quais cada professor é chamado a desempenhar, simultaneamente, o papel de formador e formando. [...] Nesse sentido, é fundamental o diálogo entre os professores.

Sobre o perfil docente, constatamos a necessidade da maioria dessas docentes atuar em dois turnos (na própria escola ou, mais comumente, em outras redes de ensino), de forma a garantir um salário digno. Infelizmente, percebe-se que este não é um fator que contribua expressivamente com a experiência qualitativa na ação pedagógica do professor para atuar nos anos iniciais, já que as professoras demonstraram um cansaço intenso e contínuo por terem que percorrer alguns extremos de distância para atuar em duas escolas. É nesse aspecto que Ribeiro e Brizola (2012) defendem a educação em tempo integral com o professor atuante em uma única escola.

Quanto à compreensão sobre a proposta metodológica e à concepção de educação que fundamenta a prática das professoras ao ensinar, de um modo geral e, particularmente, o ensino de Ciências Naturais, constatou-se que sete professoras (as que ouviram falar do construtivismo, mas não usam para ensinar) têm uma compreensão acerca dos fundamentos que alicerçam sua atuação pedagógica em sala de aula, embora ainda não consigam verbalizar de forma significativa, mas buscam compreender os procedimentos que possam desencadear de fato o aprendizado do aluno, demonstrando grande abertura em inovar a sua prática pedagógica para que se possa transcender e tornar significativo o conteúdo trabalhado. Algumas professoras verbalizaram certo desprezo ao ensino tradicional, mas sem que 
houvesse muita consistência na compreensão dos fundamentos que possam subsidiar melhor o trabalho.

Todas as professoras apresentaram dificuldades para responder às perguntas sobre a proposta metodológica que fundamentava seu trabalho em sala de aula, sobretudo em relação ao ensino de Ciências Naturais. Mesmo algumas reconhecendo que podem melhorar suas ações pedagógicas, quatro professoras afirmaram estar satisfeitas com o resultado do seu trabalho, pautado em práticas tradicionalistas, e se mostraram bastante resistentes e engessadas frente a novas propostas. As observações revelaram certa superficialidade acerca da compreensão dos aspectos teóricometodológicos que envolvem a prática docente. Para abandonar práticas tradicionais é necessário maior fundamentação dos professores que atuam nos anos iniciais, já que, em sua maioria, as professoras evidenciaram uma insegurança em abandonar a postura de se posicionar a frente da classe. Os alunos de todas as classes observadas se posicionam em formato de enfileiramento, poucas aulas despertaram motivação nas aulas de Ciências Naturais, um desafio que deve ser constantemente superado por todas as professoras que atuam na escola e que, definitivamente, não é superado com um modelo de ensino ultrapassado que privilegia a cópia do quadro, com as aulas acontecendo de forma efêmera ao longo do ano letivo.

As professoras podem aproveitar as aulas de Ciências Naturais para construir com seus alunos a oportunidade de realizar descobertas, debater e argumentar sobre o fenômeno estudado, com vistas a despertar o interesse científico em seus alunos. A reflexão acerca dessa questão leva a entender que as atividades pedagógicas propostas só têm sentido se forem desenvolvidas com orientação e de forma compreensiva, com a participação ativa dos alunos. Contudo, as observações realizadas demonstraram que a frequência de atividades com os alunos é alta, mas, em sua maioria, de maneira mecânica, não nas aulas de Ciências Naturais, e sem apresentar nenhum desafio ao aluno, sendo utilizada na maioria das vezes a cópia da matéria descrita na lousa e a realização de tarefas em folhas avulsas ou livro didático. Não foram proporcionados momentos de reflexão sobre o conteúdo trabalhado, deixando-o completamente dissociado da realidade do aluno. 
As atividades de planejamento que deveriam remeter à discussão individual, reflexiva e coletiva das professoras em torno das estratégias que utilizam e as que poderiam lançar mão em suas aulas ao ensinar Ciências Naturais, constatou-se que o individualismo, ao qual o ato de planejar se consolida, pouco contribui para uma ação mais efetiva no cotidiano dentro da escola pesquisada. O conteúdo desenvolvido nas aulas pode e deve extrapolar a discussão para fora da escola, incitando a discussão também na comunidade onde a escola está inserida, propício para a realização de descobertas. Porém, há dificuldades das professoras em desenvolver o planejamento das aulas e a seleção do conteúdo a ser trabalhado, causando insegurança na ação docente ao ensinar Ciências Naturais. As atividades extraclasses, que também exigem planejamento, devem ser preferencialmente integradas ao conteúdo trabalhado em sala de aula, já que tais atividades contribuem para a aprendizagem. Em relação a esse aspecto, Delizoicov, Angotti e Pernambuco (2002, p. 37) indicam que espaços de "divulgação científica e cultural, como museus, laboratórios abertos, planetários, parques especializados, exposições, feiras e clubes de ciência, fixos ou itinerantes, não podem ser encarados só como oportunidades de atividades educativas complementares ou de lazer".

Durante as entrevistas, as professoras destacaram que o livro didático é um recurso de fácil utilização em sala de aula, mas que nem sempre conseguem realizar as atividades propostas no livro, seja pelo fato de considerarem demorar muito tempo para desenvolvê-las, seja também por as julgarem desnecessárias ou mesmo dificeis. Nas observações em sala de aula foi possivel entender os motivos que levam as professoras a resistirem em trabalhar com as atividades propostas nos livros didáticos de Ciências Naturais, corroborando que há falta de conhecimento específico dos conceitos científicos e, principalmente, compreensão do papel das atividades prático-experimentais, problematizado por Pereira e Moreira (2017). Nesse caso, destaca-se que o conhecimento acerca do que será trabalhado é fundamental para que de fato a professora consiga romper com os planejamentos alicerçados em atividades engessadas no ensino tradicional, nos quais as professoras apenas descrevem as atividades em seus cadernos 
ou planilhas de planejamento, na maioria das vezes, sem qualquer reflexão e compreensão acerca da forma como irá consolidá-la em suas ações cotidianas. Conforme afirma Guerra (1998), “a ideia do fazer, do inventar, do criar extrapola a prática de mera transmissão de conhecimentos pelo professor e a postura de passividade do aluno na sala de aula e resgata a interação do homem com o objeto do conhecimento". A sala de aula é espaço para observar, explorar e construir, é o local ideal para lançamento de desafios, de vivências, de busca de soluções, de interações.

As entrevistas e as observações revelaram que essas professoras precisam reconhecer suas limitações, para que não utilizem apenas o que já está pronto como se fosse um roteiro fixado, uma bula ou receita a ser seguida. O planejamento e a avaliação devem constituir-se durante o processo e não somente como produto que gera um resultado ao final de um bimestre incidindo somente em critérios quantitativos. Todas as professoras utilizaram testes e provas como único instrumento de avaliação e pressionaram os alunos a alcançar os resultados esperados pela escola, e as avaliações na disciplina de Ciências Naturais corroboraram as falas das entrevistas. Isso demonstra o caminhar da prática pedagógica que deveria se orientar nos pressupostos previstos pelos Parâmetros Curriculares Nacionais (PCN), os quais propõem que o ensino de Ciências Naturais deve ser organizado de forma a colaborar para a compreensão do mundo e de suas transformações, situando o homem como um indivíduo crítico, participativo e transformador. Nesse aspecto:

Não se pode pensar no ensino de Ciências como um ensino propedêutico, voltado para uma aprendizagem efetiva em momento futuro. A criança não é cidadã do futuro, mas já é cidadã de hoje, e, nesse sentido, conhecer ciência é ampliar a sua possibilidade presente de participação social e viabilizar sua capacidade plena de participação social no futuro (BRASIL, 1997, p. 25).

O processo de avaliação não deve limitar seu foco sobre o julgamento de sucessos e fracassos discentes, mas sim compreender que este processo se constitui como um conjunto de ações empreendidas pelo docente para avaliar seus alunos e se autoavaliar, refletindo diretamente sobre sua ação pedagógica no sentido de intervir com outras ferramentas nessa ação. Não 
pode ser um fim em si mesmo, mas sim o recomeço com outro olhar, com outras estratégias, com outros recursos para atingir o sucesso escolar. O princípio que norteia uma prática pedagógica crítica e reflexiva demanda uma avaliação capaz de contribuir com a preocupação de formar o cidadão em sua plena cidadania. Esse referencial está presente nas propostas oficiais, como é o caso dos PCN de todas as disciplinas, e em especial o caderno 4, que propõe que o ensino de Ciências Naturais deve ser organizado de forma a colaborar para a compreensão do mundo e de suas transformações, situando o homem como um indivíduo crítico, participativo e transformador.

Frente aos resultados apresentados até aqui, cabe discutirmos se a disciplina de Ciências Naturais é trabalhada ou não em sala de aula, já que os relatos das professoras que atuam nos anos iniciais parecem indicar o entendimento de que o ensino ainda é concebido na visão tradicional de transmissão de conteúdos expostos nos livros didáticos, pautando sua ação em cópia da matéria apresentada no quadro, o que torna o estudo dos conteúdos científicos descontextualizados e sem significado. Vale lembrar que não se trata de todas as professoras, uma vez que constatamos que algumas se predispõem a modificar sua prática. Fica claro que as disciplinas de Matemática e Português são priorizadas pelas professoras, até pela tradição elencada a essas disciplinas, mas não se pode simplesmente desprezar os conhecimentos das Ciências Naturais, uma vez que inúmeras são as possibilidades de trabalho nessa área. Mesmo com os PCN como um documento norteador, as ações pedagógicas utilizadas pelas docentes ao ensinarem Ciências Naturais (quando ensinam) não parecem atender às necessidades dos alunos imersos na sociedade da informação do século XXI, ampliando sua visão do mundo contemporâneo.

A Lei de Diretrizes e Bases da Educação Nacional (LDBEN) no 9.394 (BRASIL, 1996), na seção III intitulada "Do Ensino Fundamental", artigo 32, parágrafo $3^{\circ}$, trata da importância do "desenvolvimento da capacidade de aprendizagem, tendo em vista a aquisição de conhecimentos e habilidades”. Nesse parágrafo, essa lei propõe e apresenta subsídios para desenvolver no educando o uso das ações e habilidades de uma pesquisa escolar, tendo em 
vista o contato e a reconstrução sistemática da informação utilizando-se da introdução do aluno na vivência científica. Em consonância com os aspectos legais em relação ao ensino de Ciências Naturais, torna-se relevante colocar em tela a afirmação de que as professoras, por falta de dominio do conteúdo de Ciências Naturais, acabam deixando de trabalhar a disciplina de forma continua, e quando o fazem utilizam práticas pedagógicas que limitam a construção do conhecimento científico pelo aluno, fazendo com que as Ciências Naturais se transformem em uma lacuna na formação escolar do aluno, que acaba por propagar certo desprezo que os estudantes desenvolvem por essa disciplina nos anos finais do ensino fundamental e pelas específicas em que se desdobra no ensino médio (biologia, física e química).

Por fim, destacamos que mesmo as professoras demonstrando ter realizado o planejamento da maioria de suas aulas, fica evidente a insegurança delas ao desenvolver sua prática pedagógica ao ensinarem Ciências Naturais, confirmando, assim, a necessidade da formação continuada para os docentes dos anos iniciais, sobretudo a partir do ensino por investigação e a utilização de atividades prático-experimentais.

\section{CONSIDERAÇÕES FINAIS}

O ensino de Ciências Naturais nos anos iniciais do EF deveria ser considerado como base no atendimento às necessidades do desenvolvimento científico e tecnológico de um país, até porque quando se tem um olhar reflexivo sobre aspectos reais que circulam no seu cotidiano, o indivíduo pode desenvolver o espírito científico e ter melhores condições de agir e criar alternativas para fundamentar sua ação, contribuindo decisivamente na formação para a cidadania, para a tomada de decisão. É preciso ultrapassar os desafios decorrentes da prática pedagógica cotidianamente desenvolvida dentro da escola. Para tanto, é preciso entender o significado desse conhecimento para os alunos desse nível de ensino, uma vez que a prioridade é dada às disciplinas de Português e Matemática. Compreende-se a importância desses conhecimentos, mas precisamos destacar que, além deles, os alunos necessitam compreender o mundo, seu contexto, as 
transformações geradas pelo homem em sua relação com a natureza, a fim de poder ressignificá-lo, desde a mais tenra idade.

Quanto aos planejamentos de ensino, realizados semanalmente e individualmente, os encontros destinados acabam não sendo momentos de trocas de experiências, questão esta considerada relevante no desenvolvimento da prática docente, pois nesse momento ocorre a sua legitimidade pedagógica baseada em um genuíno compromisso pedagógico de construção de sujeitos, e isso só ocorre quando se conhece a realidade e quando se está disposto a discuti-la e modificá-la e, consequentemente, a avaliação acaba sendo processual.

Quanto ao conteúdo desenvolvido e à metodologia pedagógica utilizados pelas professoras ao ensinarem Ciências Naturais, verificamos que os conteúdos são trabalhados a partir do livro didático ou cópias de atividades da lousa. Talvez pelo pouco conhecimento que as docentes tenham em relação ao processo de ensino e aprendizagem de Ciências Naturais, há dificuldade em trabalhar com atividades prático-experimentais. Quanto aos recursos didáticos, há grande escassez de material didáticopedagógico necessário para o desenvolvimento do trabalho cotidiano dentro da escola. Mesmo reconhecendo a importância do ensino de Ciências Naturais, os professores reclamam da falta de estrutura da escola e dos recursos para desenvolver um bom trabalho, principalmente de pesquisa, mesmo que um número significativo de docentes sinta dificuldades em desenvolver esse tipo de trabalho.

As professoras desempenham mais o papel de transmissores de informações, o que não contribui para a construção do conhecimento pelos sujeitos. Algumas desempenham, às vezes, papel de facilitadoras e/ou de mediadoras, na maioria das vezes sem consciência de sua ação. As boas práticas pedagógicas precisam ser implementadas e desenvolvidas na perspectiva ação-reflexão-ação. Se o ensino for voltado para a compreensão do seu meio, o aluno poderá ser capaz de compreender problemas básicos que dizem respeito a sua vida, como lixo, alimentação, desmatamento, saúde, preservação ambiental, higiene, entre outros. 


\section{REFERÊNCIAS}

BRANDI, A.; GURGEL, C. Alfabetização científica e o processo de ler e escrever em séries iniciais:emergências de um estudo de investigação-ação. Ciência e Educação, v. 8, n. 1, 2002.

BRASIL. Lei de Diretrizes e Bases da Educação Nacional (LDB), Lei n ${ }^{\circ}$ 9.394, 20 de dezembro de 1996. 1996.

. Parâmetros Curriculares Nacionais. Ciências Naturais. Secretaria de Educação Fundamental. Brasília: MEC/SEF, 1997.

CARVALHO, A.; GIL PÉREZ, D. O saber e saber fazer dos professores. In:

CASTRO, A.; CARVALHO, A. Ensinar a ensinar: didática para a escola fundamental e média. São Paulo: Pioneira Thomsom Learning, 2001.

DELIZOICOV, D.; ANGOTTI, J.; PERNAMBUCO, M. Ensino de ciências:

fundamentos e métodos. São Paulo: Cortez, 2002.

DURKHEIM, E. Educação e sociologia. Petrópolis: Vozes, 2011.

FREIRE, P. Pedagogia da esperança: um reencontro com a pedagogia do oprimido. 4. ed. Rio de Janeiro: Paz e Terra, 1992.

. Pedagogia da autonomia: saberes necessários à prática educativa. 22.

ed. São Paulo: Paz e Terra, 1996.

GUERRA, D. Experimentando e descobrindo ciências. Salvador: Tamta, 1998. HERNÁNDEZ, F.; VENTURA, M. A organização do currículo por projetos de trabalho: o conhecimento é um caleidoscópio. 5. ed. Porto Alegre: Artes Médicas, 1998.

NÓVOA, A. Os professores e a sua formação. Lisboa: Instituto de Inovação Educacional, 1995.

. O passado e o presente dos professores. In: NÓVOA, A. Profissão professor. 2. ed. Porto: Porto, 1999.

PEREIRA, M. V.; MOREIRA, M. C. do A. Atividades prático-experimentais no ensino de Física. Caderno Brasileiro de Ensino de Física, v.34, n.1, 2017. RIBEIRO, D.; BRIZOLA, L. Entre os discursos e o vivido: as encruzilhadas. In: REIS, M. (Org.). Educação integral emancipatória e trabalhista. PDT Projeto Brasil Trabalhista, Cartilhas Trabalhistas, v. 4, Brasília, 2012. TARDIF, M. Saberes docentes e formação profissional. Petrópolis: Vozes, 2002. 